\title{
Primary Immunization among Children in Malaysia: Reasons for Incomplete Vaccination
}

Noor Ani Ahmad ${ }^{1}$, Rohani Jahis ${ }^{2}$, Lim Kuang Kuay ${ }^{1}$, Rasidah Jamaluddin ${ }^{1}$ and Tahir Aris ${ }^{1}$

${ }^{1}$ Institute for Public Health, Ministry of Health Malaysia, Malaysia

${ }^{2}$ Disease Control Division, Ministry of Health Malaysia, Malaysia

"Corresponding author: Noor Ani Ahmad, Centre for Family Health Research, Institute for Public Health, Ministry of Health Malaysia, Jln Bangsar, 50590 Kuala Lumpur, Malaysia, Tel: +603-22979400/441; Fax: +602-22823114; E-mail: drnoorani@moh.gov.my

Received date: April 24, 2017; Accepted date: May 02, 2017; Published date: May 08, 2017

Copyright: $\odot 2017$ Ahmad NH, et al. This is an open-access article distributed under the terms of the Creative Commons Attribution License, which permits unrestricted use, distribution, and reproduction in any medium, provided the original author and source are credited.

\section{Abstract}

Objective: Incomplete primary immunization against vaccine preventable diseases is a significant public health problem. This study aimed to identify population at-risk for incomplete immunization and their associated factors.

Methods: Data on immunization module from the National Health and Morbidity Survey (NHMS) 2016 was analysed. This survey was conducted as a nation-wide community based survey using stratified random sampling design. Immunization history of children aged 12 to 23 months from the randomly selected addresses were taken from their mothers by face-to-face interview using mobile device. The information was verified with vaccination cards.

Results: Out of 11,388 eligible respondents, 10,140 responded to the survey; $89.0 \%$ response rate. The prevalence of incomplete immunization was $4.5 \%$, while non-immunised was $0.1 \%$. Logistic regression analysis revealed that children at-risk of incomplete immunization or being non-immunised were girls, residing in urban areas, have mothers who do not believe that vaccine can prevent spread of disease and mothers who had pregnancy care at private healthcare facilities. Among reasons given for incomplete or non-uptake of immunization were due to either private healthcare facilities reasons; vaccine stock shortage or not due for immunization yet, or personal reasons; 'no time', forgotten', 'refused vaccine', and 'doubt halal status'.

Conclusion: Children with incomplete immunization in Malaysia were more likely to come from urban areas and received care at private healthcare facilities. A standard schedule for all healthcare facilities and single registry may be suitable strategies to be implemented, in order to ensure high vaccination coverage in Malaysia.

Keywords: Immunization; Incomplete primary vaccination; Vaccine hesitancy; Vaccination coverage; Survey; Community-based; Malaysia

\section{Introduction}

Immunization is one of the most cost-effective strategies in reducing child mortality. Global Vaccine Action Plan (GVAP), endorsed by 194 member states of World Health Assembly, was launched in 2012 with the aim to strengthen the immunization coverage, towards $90 \%$ coverage, while reducing under-five mortality rate [1]. However, in 2015, World Health Organization (WHO) estimated that only $86 \%$ of the world's children received three doses of diphtheria-tetanuspertussis (DTP3) vaccine, while an estimated 19.4 million infants did not [2].

Immunization coverage in Western Pacific Region in 2015, using DPT3 coverage as the proxy, ranges from as low as $60 \%$ in Philippine, Papua New Guinea and Samoa to as high as $100 \%$ in Singapore, Malaysia and Vietnam [3]. The mentioned coverage might not be accurate as WHO had expressed their concern on the discrepancies between WHO-UNICEF coverage estimates, country official estimates and administrative data reported [4]. Member's countries were suggested to increase the quality of coverage monitoring through revision of reporting framework, implementation of high quality coverage survey or digitization of immunization information using registry.

Various studies indicated that mothers who have low education levels, low household income or lack of faith in vaccines are less likely to fully immunize their children [5,6]. In Malaysia, in spite of the persistent high immunization coverage of above $90 \%$ reported based on the administrative data, outbreaks of vaccine-preventable diseases such as measles and diphtheria still occur sporadically $[7,8]$. The outbreaks might have happened as a result of low herd immunity due to poor immunization coverage or low seroconversion of vaccine. A 2006 study focusing on primary immunization coverage in the state of Sabah noted a defaulter rate of $16.8 \%$, with working mothers found as one of the factors associated with defauters [9]. A seroprevalence study done in Seremban district in Malaysia revealed a seropositive rate for measles to be $87 \%$ [10]. In Malaysia, based on the Ministry of Health's vaccination schedule, children aged 12 months are recommended to receive eight basic primary immunization; BCG, Hepatitis Dose 1, 2 and 3, Diphteria-Tetanus-Pertussis-Haemophilus Influenza Dose 1, 2 and 3, and Measles-Mumps -Rubella.

The possibility of low level of immunization coverage in Malaysia warrants a national community-based survey. Thus, this study aimed to determine the actual prevalence of incomplete or no-uptake of 
primary immunization among children below 2 years in Malaysia and to identify its contributing factors.

\section{Methods}

\section{Study design and sampling}

This study is part of the National Health and Morbidity Survey (NHMS) 2016, conducted on a regular basis to supplement existing data and provide data for monitoring and evaluation of health programmes in Malaysia. This survey was targeted towards Malaysian residents in non-institutionalised living quarters in both urban and rural areas from all 13 states and 2 Federal Territories in Malaysia. In NHMS 2016, sample was selected from the database of live births in Malaysia registered with the National Registration Department. This database includes both citizens and non-citizens and was updated as a single registry in Malaysia, which is suitable to be used as a sampling frame for a national survey.

Sample size was calculated based on a single proportion formula for prevalence estimation. As we do not know the actual prevalence of complete primary immunization among children aged 12-23 months in Malaysia, sample size calculation was based on $50 \%$ estimated prevalence and design effect of 1.5. Based on these variables, the required sample size for single strata analysis was 576 . However, to ensure analysis can be done at state level, sample size was multiplied by 15 , resulting in 8,640 live births. To compensate for $50 \%$ expected nonresponse, the required sample size was inflated to 17,330 , which were then allocated to the states in equal proportion [11].

This survey used a stratified sampling design to ensure national representativeness. Based on this design, states and Federal Territories were considered as Primary Stratum, while districts within the states were considered as Secondary Stratum. All states and Federal Territories were included in this survey, and all districts within the states were identified. Sampling Unit was the living quarters within the districts. Random selection within the districts was done proportionately based on the frame of living quarters or addresses of mothers who had their last child birth within 2 years, based on National Registration Department database.

Invitation letters together with consent form, information sheet and pamphlet about the survey, were sent to the selected respondents. Nurses from the districts, based on the Ministry of Health's personalised-care programme, visited the selected living quarters and explained more about the survey and obtained written consent for the interview. Individuals who consented individuals were then invited to join the survey and respond to the questionnaires.

\section{Questionnaire}

The first part of the module, on immunization received by the children, was based on the Multiple Indicator Cluster Survey (MICS) questionnaire developed by the UNICEF [12]. Permission to use this questionnaire was granted by UNICEF prior to the survey. The second part of the module, on vaccine acceptance, was adapted from the WHO questionnaire [13]. The questionnaire was administered as a bilingual questionnaire; Bahasa Malaysia and English. The Bahasa Malaysia version of questionnaire was translated from English by content experts with fluency in English. The questionnaire was then back-translated to English by English-speaking experts with fluency in Bahasa Malaysia. The Bahasa Malaysia version was pilot tested in 30 individuals from three major ethnicities in Malaysia; Malay, Chinese and Indians, and from both low and highly educated individuals. No problems were found in term of comprehension of the questionnaire content and wording. The questionnaire was then used in the survey and administered as a face-to-face interview using mobile devise.

This module was only applicable to respondents who had children aged 12 to 23 months at the time of interview. The first part of the module assessed the immunization status of the child, focussing on the eight basic primary immunization recommended by the Ministry of Health Malaysia; BCG, Hepatitis Dose 1, 2 and 3, Diphteria-TetanusPertussis-Haemophilus Influenza Dose 1, 2 and 3, and Measles-Mumps -Rubella. The information given by the respondents were then verified with the Child Home-based Card if available. Information on health facilities where they received the immunization; either private or government, and the date immunization received was noted too. Opinion and belief on vaccines were explored. Reasons for noncompliance were asked to those who did not complete their immunization based on the recommended schedule. Another module, a household module, was also covered. This module collected information on the household characteristics and income. Information on antenatal, intrapartum and postnatal care was also asked about.

\section{Statistical Analysis}

Data was analysed using complex sample module in the IBM Statistical Package of Social Sciences (SPSS) for Windows version 23.0 (IBM Corp., Armonk, NY, USA), taking into consideration the complexity of the sampling design. The prevalence of incomplete immunization and their estimated population affected were then determined. Bivariate analysis was done looking into the association between sociodemographic profile of the parents, antenatal, intrapartum and postnatal care and belief on vaccines, with incomplete immunization. Crude odds ratios were used to describe the strength of association between dependent and independent variables. Mutivariable logistic regression model was fitted to determine the factors associated with incomplete immunization. The independent variables that were included were locality, sex, ethnicity, citizenship, household income, maternal profiles: age group, marital status, education level and occupation; paternal profile: education level and occupation, healthcare providers during antenatal care, and belief on vaccine. As the dependent variable was dichotomous, logistic regression model was used to produce crude odds ratio as a measure of association. For the final model, FORWARD LR variable selection method was used to obtain significant variables. Only variables with $\mathrm{p}$ value of less than 0.25 were included. The statistical significance of the individual regression coefficient was tested using Wald chi-square statistic. The adjusted OR, with their respective 95\% confidence intervals (CIs), was then calculated. A p-value of less than 0.05 was considered significant in the final model.

\section{Variable definition}

Incomplete immunization was defined as missing any of the listed vaccines among children aged 12-23 months, while non-immunised was defined as did not receive any of the listed vaccines. Verified complete immunization was defined as those reported as having received all of the listed vaccines and can be verified by home-based cards, while self-reported complete immunization was those who reported received all immunizations but could not be verified with any documentation. 
Page 3 of 8

In our survey, locality was categorized into urban or rural areas based on the Department of Statistics Malaysia's definition: urban area is defined as area with population above 10,000 and at least $60 \%$ of its population aged above 15 years involved in non-agricultural activities. Ethnicity was classified based on three major ethnic groups in Malaysia, namely Malay, Chinese and Indian, followed by 'Other Bumiputera' and 'Others'. 'Other Bumiputera' comprises of indigenous groups, local Sabahans and Sarawakians, while 'Others' were mostly foreigners, immigrants, both legal and illegal, residing in Malaysia. For children, their ethnicity was based on paternal ethnicity. Ethnic composition of the samples was adjusted using post-stratification weight to ensure similar composition with ethnic distribution in Malaysia. Citizenship was categorized into either Malaysian citizens or non-Malaysians.

Maternal age was grouped into three categories; 18-25 years, 25-39 years, and 40 years and above. Only mothers aged 18 years and above were eligible to be included in this study. Maternal marital status was categorised into single, married or cohabiting with partner, separated or divorced, or widowed. Maternal and paternal education levels were based on the Malaysian education system. Respondents were considered as having no formal education if they had not attended any formal schooling while those who had completed up to six years of primary school were considered as having attained primary education. Those who had completed 11 years of formal schooling were considered as having completed secondary education. Respondents with diploma or higher qualifications were considered as having completed tertiary education. Occupation of the parents or head of the household was grouped into either working in public sector, private sector, self-employed or housewife/unemployed. Household income was calculated based on the pooled income of family members and divided into quintiles; with the first quintile representing the poorest $20 \%$ and fifth quintile representing the richest $20 \%$.

\section{Ethics Approval}

This survey was reviewed and approved by the Medical Research and Ethics Committee Malaysia (NMRR-15-511-25359). All respondents were provided with an information sheet and a copy of the signed consent form. For those who are illiterate, the information sheet and consent form were read to them and thumb print impression was taken to replace their signature in the presence of an impartial witness.

\section{Results}

Out of 17,275 living quarters selected, 11,388 were eligible, but only 10,140 responded during the survey, with an $89.0 \%$ response rate. The non-eligible included those who had moved out from the registered address or whose addresses were not found. Mean age of the children was 17.5 months (range 12 to 23 months). More than half of the respondents were from urban areas, and majority of them were Malaysian. Majority of the mothers were between the ages of 25 to 39 years with mean age of 31 years. Detailed characteristics of the children' parents are shown in Table 1.

\begin{tabular}{|l|l|l|}
\hline \multicolumn{2}{|l|}{$\begin{array}{l}\text { Unweighted } \\
\text { count }\end{array}$} & Percent (\%) \\
\hline Mean Age (months ) & 17.50 (SD: 2.45) \\
\hline Locality & 6,019 & 59.36 \\
\hline Urban &
\end{tabular}

\begin{tabular}{|c|c|c|}
\hline Rural & 4,121 & 40.64 \\
\hline \multicolumn{3}{|l|}{ Sex } \\
\hline Male & 5,240 & 51.68 \\
\hline Female & 4,900 & 48.32 \\
\hline \multicolumn{3}{|l|}{ Ethnicity } \\
\hline Malay & 7,136 & 62.8 \\
\hline Chinese & 1,222 & 14 \\
\hline Indians & 437 & 4.5 \\
\hline Other Bumiputera & 1,133 & 12.7 \\
\hline Others & 212 & 6 \\
\hline \multicolumn{3}{|l|}{ Citizenship } \\
\hline Malaysian citizen & 9,973 & 98.35 \\
\hline Non-Malaysian & 167 & 1.65 \\
\hline \multicolumn{3}{|l|}{ Age of mother (years) } \\
\hline $18-25$ & 1,196 & 11.9 \\
\hline $25-39$ & 8,215 & 81.8 \\
\hline 40 or more & 637 & 6.28 \\
\hline \multicolumn{3}{|l|}{ Marital status of mother } \\
\hline Single & 32 & 0.3 \\
\hline Married/cohabiting & 9,904 & 98.2 \\
\hline Separated/divorced & 131 & 1.3 \\
\hline Widowed & 25 & 0.3 \\
\hline \multicolumn{3}{|l|}{ Mother's education } \\
\hline No formal/Primary education & 1250 & 12.4 \\
\hline Secondary education & 5,235 & 52 \\
\hline Tertiary education & 3,580 & 35.6 \\
\hline \multicolumn{3}{|l|}{ Father's education } \\
\hline No formal/Primary education & 1360 & 14.1 \\
\hline Secondary education & 5,295 & 54.9 \\
\hline Tertiary education & 2,996 & 31 \\
\hline \multicolumn{3}{|l|}{ Mother's Occupation } \\
\hline Public Sector & 2,427 & 24.1 \\
\hline Private Sector & 2,255 & 22.4 \\
\hline Self-employed & 764 & 7.6 \\
\hline Housewife/Unemployed & 4,626 & 45.9 \\
\hline \multicolumn{3}{|l|}{ Father's Occupation } \\
\hline Public Sector & 2,338 & 24.2 \\
\hline Private Sector & 4,594 & 47.5 \\
\hline
\end{tabular}




\begin{tabular}{|l|l|l|}
\hline Self-employed & 2,657 & 27.5 \\
\hline Unemployed & 88 & 0.9 \\
\hline Household income & 2,046 & 20.3 \\
\hline Q1 (poorest 20\%) & 2,046 & 20.3 \\
\hline Q2 & 2,074 & 20.6 \\
\hline Q3 & 2,024 & 20.1 \\
\hline Q4 & 1,885 & 18.7 \\
\hline Q5 (richest 20\%) & & \\
\hline
\end{tabular}

Table 1: Sociodemographic profile of children 12-23 months, Malaysia NHMS $2016(n=10,140)$.

Based on the analysis, $86.4 \%$ of children aged $12-23$ months were verified as having completed their primary immunization, with an additional $8.9 \%$ self-reported as having completed their primary immunization. A total of $4.5 \%$ of children did not complete all recommended primary immunizations by the age of 12 months with another $0.1 \%$ who did not receive any vaccination. Based on the prevalence of $4.62 \%$ (95\% Confidence interval, CI: $4.00,5.33$ ), an estimated 23,610 children aged 12-23 months in Malaysia did not complete their primary immunization or did not receive any immunization by the age of 12 months.

Bivariate analysis noted that the prevalence of incomplete immunization was $23 \%$ higher among girls as compared to boys, four times higher among other ethnics as compared to the Malays, five times higher among non-Malaysians as compared to the Malaysians,

and more likely among those from urban areas as compared to those from rural areas. By income distribution, the prevalence was lower among those from the lower quintile, Q1 to Q3, as compared to those within Q5, the richest 20\%. The prevalence was also lower among children of parents with secondary education level as compared to those with tertiary education level. Our study also observed that incomplete immunization was 14 higher among those children whose parents did not trust vaccines as being protective as compared to those who did, 11 times higher among those whose parents did not trust that vaccines can prevent spread of diseases as compared to those who did, and 14 times higher among children whose parents did not trust the vaccine safety as compared to those who did. Incomplete immunization was also seven times higher among children whose mothers received antenatal care at private facilities. There is no association between incomplete immunization and maternal age, maternal marital status, or parents' occupation (Table 2).

On further examination, logistic regression analysis found those only four factors; child's gender, locality, trust that vaccines prevent spread of diseases and antenatal care at private facilities, were significantly associated with incomplete primary immunization among children 12-23 months when other variables were adjusted for. Girls were more likely, $63 \%$ higher, than boys for not receiving all scheduled vaccination by 12 months old, while those who reside in urban areas were three times at higher risk of not completing their primary immunization as compared to those from rural areas. Children whose mothers do not trust that vaccines can prevent spread of diseases were three times at higher risk of incomplete immunization. In addition, children with mothers who had received antenatal care at private facilities were seven times at higher risk of incomplete primary immunization (Table 2).

\begin{tabular}{|c|c|c|c|c|c|c|c|c|}
\hline & \multirow{2}{*}{$\begin{array}{l}\text { Unweighted } \\
\text { count }\end{array}$} & \multirow[t]{2}{*}{ Prevalence (\%) } & \multicolumn{2}{|l|}{$95 \% \mathrm{Cl}$} & \multirow{2}{*}{$\begin{array}{l}\text { Crude OR } \\
(95 \% \mathrm{Cl})\end{array}$} & \multirow[t]{2}{*}{ Wald } & \multirow[t]{2}{*}{ Adjusted OR $(95 \% \mathrm{Cl})$} & \multirow[t]{2}{*}{$p$ value } \\
\hline & & & Lower & Upper & & & & \\
\hline \multicolumn{9}{|l|}{ Gender } \\
\hline Male & 179 & 3.61 & 2.93 & 4.46 & $\mathrm{R}$ & & $\mathrm{R}$ & \\
\hline Female & 204 & 5.69 & 4.68 & 6.9 & $1.23(1.00,1.51)$ & 6.53 & $1.63(1.12,2.37)^{\star}$ & 0.011 \\
\hline \multicolumn{9}{|l|}{ Ethnicity } \\
\hline Malay & 262 & 4.56 & 3.8 & 5.46 & $\mathrm{R}$ & & & \\
\hline Chinese & 46 & 4.08 & 2.7 & 6.1 & $1.03(0.74,1.41)$ & & & \\
\hline Indian & 14 & 1.99 & 1.11 & 3.55 & $0.87(0.50,1.50)$ & & & \\
\hline $\begin{array}{l}\text { Other } \\
\text { Bumiputera }\end{array}$ & 32 & 3.54 & 2.42 & 5.16 & $0.79(0.54,1.14)$ & & & \\
\hline Others & 28 & 10.82 & 6.75 & 16.91 & $3.99(2.63,6.05)$ & & & \\
\hline \multicolumn{9}{|l|}{ Citizenship } \\
\hline $\begin{array}{l}\text { Malaysian } \\
\text { citizen }\end{array}$ & 356 & 4.31 & 3.7 & 5.02 & $\mathrm{R}$ & & & \\
\hline Non-Malaysian & 27 & 11.01 & 7.1 & 16.7 & $5.21(3.40,7.96)$ & & & \\
\hline \multicolumn{9}{|l|}{ Locality } \\
\hline Urban & 272 & 5.4 & 4.55 & 6.39 & $1.71(1.37,2.14)$ & 11.39 & $2.70(1.52,4.81)^{\star}$ & 0.001 \\
\hline
\end{tabular}


Citation: Ahmad NA, Jahis R, Kuay LK, Jamaluddin R, Aris T (2017) Primary Immunization among Children in Malaysia: Reasons for Incomplete Vaccination. J Vaccines Vaccin 8: 358. doi:10.4172/2157-7560.1000358

Page 5 of 8

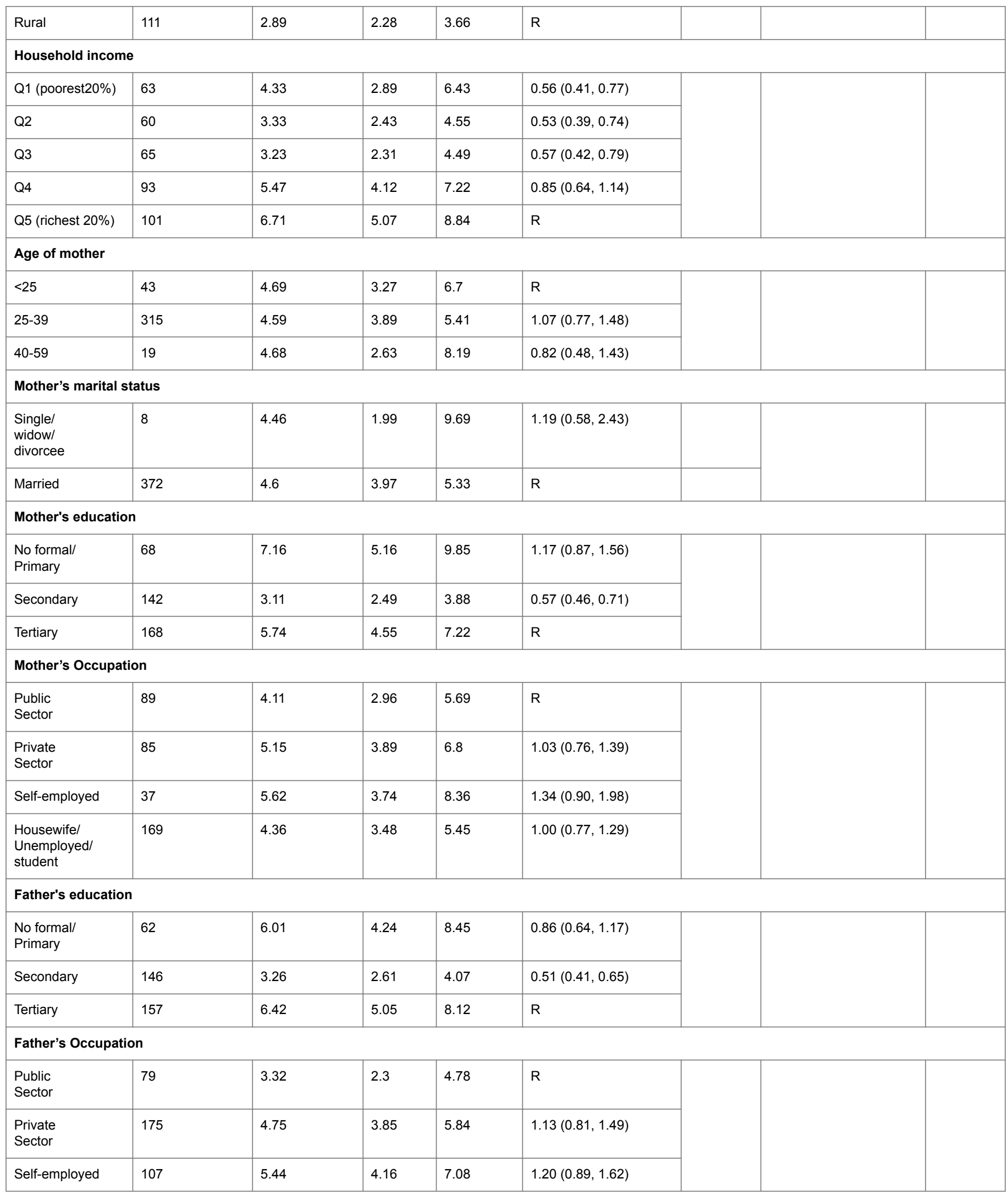


Citation: $\quad$ Ahmad NA, Jahis R, Kuay LK, Jamaluddin R, Aris T (2017) Primary Immunization among Children in Malaysia: Reasons for Incomplete Vaccination. J Vaccines Vaccin 8: 358. doi:10.4172/2157-7560.1000358

Page 6 of 8

\begin{tabular}{|c|c|c|c|c|c|c|c|c|}
\hline $\begin{array}{l}\text { Housewife/ } \\
\text { Unemployed/ } \\
\text { student }\end{array}$ & 5 & 5.74 & 2.22 & 14.02 & $1.72(0.68,4.37)$ & & & \\
\hline \multicolumn{9}{|c|}{ Trust vaccine as protective } \\
\hline Yes & 335 & 4.14 & 3.54 & 4.83 & $\mathrm{R}$ & & & \\
\hline No & 38 & 32 & 21.05 & 45.35 & $14.43(9.63,21.61)$ & & & \\
\hline \multicolumn{9}{|c|}{ Trust vaccine can prevent infectious disease } \\
\hline Yes & 332 & 4.04 & 3.45 & 4.72 & $\mathrm{R}$ & & & \\
\hline No & 42 & 30.33 & 20.63 & 42.16 & $10.77(7.44,15.61)$ & 4.06 & $2.83(1.03,7.78)^{*}$ & 0.044 \\
\hline \multicolumn{9}{|c|}{ Trust vaccine is safe } \\
\hline Yes & 325 & 4.01 & 3.42 & 4.7 & $\mathrm{R}$ & & & \\
\hline No & 48 & 33.27 & 23.18 & 45.17 & $13.68(9.55,19.59)$ & 3.62 & $2.91(0.97,8.76)$ & 0.057 \\
\hline \multicolumn{9}{|c|}{ Antenatal care at private } \\
\hline Yes & 130 & 8.68 & 6.88 & 10.89 & $6.85(2.16,21.67)$ & 7.54 & $7.22(1.76,29.60)^{*}$ & 0.006 \\
\hline No & 3 & 0.83 & 0.22 & 3.06 & $\mathrm{R}$ & & & \\
\hline \multicolumn{9}{|l|}{ Type of birth } \\
\hline $\begin{array}{l}\text { Spontaneous } \\
\text { delivery }\end{array}$ & 279 & 4.62 & 3.89 & 5.48 & $\mathrm{R}$ & & & \\
\hline $\begin{array}{l}\text { Instrumental } \\
\text { delivery }\end{array}$ & 15 & 4.07 & 2.27 & 7.19 & $1.40(0.82,2.38)$ & & & \\
\hline $\begin{array}{l}\text { Caesarean } \\
\text { Section }\end{array}$ & 78 & 4.31 & 3.12 & 5.92 & $0.93(0.72,1.21)$ & & & \\
\hline
\end{tabular}

Table 2: Children 12-23 months with incomplete immunisation status, Malaysia NHMS 2016.

Out of the total 383 respondents who admitted to not completing their child's primary immunization as scheduled, 220 respondents declared their reasons. Almost one-third of the given reasons were due to respondents' lackadaisical attitude; $19.9 \%$ as 'no time' and $10.0 \%$ as 'forgotten', with more than $10 \%$ due to vaccine refusal, while another $16.6 \%$ did not complete their child's primary immunization due to financial or geographical barrier. Other reasons stated by respondents are shown in Table 3.

\begin{tabular}{|l|l|l|}
\hline Reasons & Unweighted count & Prevalence (\%) \\
\hline No time & 36 & 19.9 \\
\hline Child unwell & 56 & 17.3 \\
\hline Cost/transport & 25 & 16.6 \\
\hline No vaccine stock at private facilities & 14 & 10.7 \\
\hline Forgotten & 25 & 10 \\
\hline Not due yet at private facilities & 11 & 6.2 \\
\hline Refused vaccine & 9 & 4 \\
\hline Don't trust vaccine & 7 & 2.1 \\
\hline Allergic & 6 & 1.5 \\
\hline
\end{tabular}

\begin{tabular}{|l|l|l|}
\hline Doubt 'halal** & 4 & 1.3 \\
\hline Worried about side effects & 5 & 2.4 \\
\hline Religion does not allow & 3 & 0.9 \\
\hline Bad experience & 2 & 0.6 \\
\hline Others & 17 & 6.5 \\
\hline ** permissible to use according to Islamic law \\
\hline
\end{tabular}

Table 3: Reasons given by parents for incomplete immunisation $(n=220)$.

\section{Discussion}

Our survey found that $4.6 \%$ of children aged $12-23$ months were reported as not completing their primary immunization as scheduled. Another $8.6 \%$ were self-reported as having completed their primary immunization but were unable to produce documentation for verification. As such, there is a possibility of higher prevalence of incomplete immunization if we combine these two figures. However, the prevalence of incomplete primary immunization among children in Malaysia is still low as compared to Vietnam, $24.4 \%$ in 2014 [14], and Thailand, 25\% in 2012 [15], and countries in the African region which ranged from $28.3 \%$ to $62.8 \%$ [16-18] which used similar tools 
and methodology. The prevalence of incomplete immunization in our study is observed to be slightly higher than the prevalence in United Kingdom; 3.3\% incomplete immunization and $1.1 \%$ not immunised [19].

Our study found that girls were at risk of not receiving primary immunization as scheduled, compared to boys. This finding is contradictory to the findings from the study of defaulters in Sabah, Malaysia, which found higher defaulter rates among boys [9], while another study in Kenya did not show any association between the child's sex and immunization status [18]. Possible reasons for this sex difference might be due to parents who tend to perceive that girls will be more susceptible to side effects of vaccine such as fever and delay the immunization to a later date if girls were noted to be unwell and subsequently forgotten. Our study found that almost one-fifth of the mothers stated 'child unwell' as the reason given for not completing immunization as scheduled.

Various studies described the association between disadvantaged groups; ethnic minority, single parent, young or old maternal age, low household income, and low parental education status with incomplete immunization [9,16-21]. However, this association were not observed in our study. Possible reasons for this might be due to widely accessible services with widespread healthcare facilities in Malaysia. In Malaysia, immunization services are provided by both government and private healthcare facilities. The primary healthcare system in Malaysia is recognised as exemplary for other developing countries. World Health Report 2000 ranked Malaysia as number 49 from 191 WHO member countries in the overall health system performance [22]. Despite this, there was a small percentage of mothers, $16.6 \%$, who cited financial or geographical barriers as the reasons for incomplete immunization.

Our study noted a significantly higher prevalence of incomplete immunization among children from urban areas and those children whose mothers sought care during pregnancy at private clinics. It is postulated that mothers who had antenatal care at private healthcare facilities tend to continue their child care at the same facilities. A study in Brazil also found that incomplete immunization was associated with having received vaccination from private healthcare providers [23]. In Brazil, the association was explained by the household income of the respondents, where wealth inequalities resulted in poor accessibility to immunization service. In Malaysia, most of the private healthcare facilities are located in urban area. These private healthcare providers are not bound to follow the government immunization schedule. Based on the Ministry of Health Malaysia schedule, eight vaccinations are scheduled for children from birth until they reach 12 months, comprising of BCG and Hepatitis B Dose 1 at birth, Hepatitis B Dose 2 at one month, DTaP, Hib and Polio at 2, 3 and 4 months, Hepatitis B Dose 3 at 6 months and MMR at 12 months [24]. However, some private healthcare providers might have different immunization schedules or had problems with vaccine supply during the global stock-out of DTaP combined vaccines in late 2015 and 2016. Our study revealed that $10.7 \%$ of the children who did not complete their primary immunization gave reason of lack of vaccine stock at private facilities and another $6.2 \%$ reported as not due yet as advised by the private healthcare centres. Thus, a standard immunization schedule for all children, irrespective of public or private facilities, should be implemented and enforced in Malaysia. The introduction of a single database or immunization registry may also encourage continuity of care for these children.

The relationship between mothers' negative perception and belief towards vaccine; i.e. 'do not trust that vaccine are able to prevent spread of diseases' and/or 'do not trust vaccine safety', as seen in our study, is also observed in another study [17]. Our study also revealed two worrying reasons for incomplete immunization; i.e. the attitude of the mother towards their children's healthcare, presenting as 'no time' or 'forgot' their child's immunization, and those mothers in the vaccine-refusal group; who gave reasons of 'refused vaccine', 'do not trust vaccine', 'doubt halal status', 'religion does not allow' and 'bad experience'. More concerted efforts should be targeted towards these groups through various channels and approaches; strengthening awareness and knowledge through various platforms including social media for the first group, while focussing on changing beliefs and perceptions of the second group through involvement of religious bodies and respected leaders in the community. The relationship between their belief and practice can be explained by the well-known health-seeking behaviour model, The Health Belief Model Theory which relates how people perceive disease severity, likelihood of contracting the disease and benefit of taking the preventive action, with their health-seeking behaviour, which is immunization in this study [25]. In contrast, a study in Congo showed no association between mothers' attitude towards vaccination with their child's immunization status [26]. Review observed various interventions such as reminder/recall systems, community-based education, incentives and immunization policies that have been implemented to reduce parental vaccine refusal and vaccine hesitancy. However, the review shows no convincing evidence on the effectiveness of the various strategies [27]. Mandating primary immunization might be the only way towards sustaining herd immunity of the population. On the other hand, we have to balance justification of this act which contributes to the benefit of the community, with individual rights.

\section{Limitations of this Study}

Immunization status of some children was not able to be ascertained as they do not have proper documentation for verification. There is a possibility that this group might not have received immunization as scheduled and thus escaped our analysis for identification of at-risk children for incomplete immunization.

There is also the possibility of missing out some underserved populations with unregistered births which is not included in our sampling frame as our survey only used the sampling frame from the National Registry Department of Malaysia.

\section{Conclusion}

Children who did not receive complete primary immunization at the age of 12 months were more likely to be girls, from urban areas, belonging to mothers who do not trust that vaccines can prevent spread of diseases, and received care at private facilities. This study identifies challenges and gaps in ensuring high immunization coverage in Malaysia toward reducing child morbidity and mortality.

\section{Conflict of Interest}

The authors declare no conflict of interest.

\section{Financial Support}

This study was sponsored by the Ministry of Health Malaysia Research Grant. 
Citation: Ahmad NA, Jahis R, Kuay LK, Jamaluddin R, Aris T (2017) Primary Immunization among Children in Malaysia: Reasons for Incomplete Vaccination. J Vaccines Vaccin 8: 358. doi:10.4172/2157-7560.1000358

Page 8 of 8

\section{Acknowledgement}

The authors wish to thank the Director General of Health Malaysia for permission to publish this study.

\section{References}

1. Global Vaccine Action Plan 2011-2020. WHO/IVB ISBN_978_92_150498_0. World Health Organization.

2. World Health Organization (2017) Immunization coverage.

3. World Health Organization. Immunization coverage country punchcards, 2015.

4. World Health Organization (2016) Meeting Report: 25th Meeting of the Technical Advisory Group on Immunization and Vaccine-Preventable Diseases in the Western Pacific Region. Manila.

5. Bondy JN, Thind A, Koval JJ, Speechley (2009) Identifying the determinants of childhood immunization in Philippines. Vaccine 27: 169-175.

6. Kumar D, Aggarwal A, Gomber S (2010) Immunization status of children admitted to a tertiary-care hospital of North India: Reasons for Partial Immunization or Non-immunization. J Health Popul Nutr 28: 300-304.

7. Ministry of Health Malaysia (2013) Childhood Immunization Coverage.

8. Abdullah AC, NorAfiah MZ, Rosliza AM (2016) Practice of childhood immunizations among parents and their assocated factors in Hulu Langat, Selangor, Malaysia. Int J Public Health and Clinical Sciences 3: 6.

9. Shamsul Azhar S, Nirmal K, Nazarudin S, Rohaizat H, Azimatun Noor A, et al. (2012) Factors influencing Childhood Immunization Defaulters in Sabah, Malaysia. Int Med J Malaysia 11.

10. Hazlina Y, Marlindawati MA, Shamsuddin K (2016) Serological assessment of the establishment of herd immunity against measles in a health district in Malaysia. BMC Infectious Diseases 16: 740.

11. Institute for Public Health (2016) National Health and Morbidity Survey, NHMS 2016: Maternal and Child Health Survey. Volume 1: Methodology and General findings.

12. UNICEF MICS5 Tool (2016) Questionnaire for Children Under Five.

13. World Health Organization (2013) The determinants of vaccine hesitancy: sample survey questions.
14. General Statistics Office and UNICEF (2014) Viet Nam Multiple Indicator Cluster Survey 2014, Key Findings. HaNoi, Viet Nam.

15. Thailand National Statistic Office and UNICEF (2012) Thailand Multiple Indicator Cluster Survey 2012. Executive Summary.

16. Jani JV, De Schascht C, Jani IV, Bjune G (2008) Risk factors for incomplete vaccination and missed opportunity for immunization in rural Mozambique. BMC Public Health 8: 161-168.

17. Abdulraheem IS, Onajole AT, Jimoh AAG, Oladipo AR (2011) Reasons for incomplete vaccination and factors for missed opportunities among rural Nigerian children. J Public Health and Epid 3: 194-203.

18. Mutua MK, Kimani-Murage E, Ettarh RR (2011) Childhood vaccination in informal urban settlements in Nairobi, Kenya: who gets vaccinated? BMC Public Health 11: 6.

19. Samad L, Butler N, Peckham C, Bedford H (2006) Incomplete immunization uptake in infancy: Maternal reasons. Vaccine 24: 6823-6829.

20. Chhabra P, Nair P, Gupta A, Sandhir M, Kannan AT (2007) Immunization in urbanized villages of Delhi. Indian J Pediatrics 74 131-1343.

21. Ibnouf AH, Van de Borne HW, Maarse JAM (2007) Factors influencing immunization coverage among children under five years of age in Khartoum State, Sudan. SA Fam Pract 49: 14

22. Chai PY, Whynes DK, Sach TH (2008) Equity in health care financing: the case of Malaysia. Int J Equity in Health 7: 15.

23. Barata RB, Sampaio de Almeida Ribeiro MC, de Moraes JC, Flannery B (2012) Socioeconomic inequalities and vaccination coverage: results of an immunization coverage survey in 27 Brazilian capitals, 2007-2008. J Epidemiol Community Health.

24. Ministry of Health Malaysia. National Immunization Schedule.

25. Carpenter CJ (2010) A meta-analysis of the effectiveness of Health Belief Model variables in predicting behaviour. Health Promotion 25: 661-669.

26. Mapatano MA, Kayembe K, Piripiri L, Nyandwe K (2008) Immunizationrelated knowledge, attitudes and practices of mothers in Kinshasa, democratic Republic of the Congo. SA Fam Pract 50: 61.

27. Sadaf A, Richards JL, Glanz J, Salmon DA, Omer SB (2013) A systematic review of interventions for reducing parental vaccine refusal and vaccine hesitancy. Vaccine 31: 4293-4304. 